\title{
Archéopages
}

Archéopages Archéologie et société

39 | 10/2013-01/2014

Le sort des vaincus

\section{Un programme original de colombier}

\section{Victorine Mataouchek}

\section{OpenEdition}

\section{Journals}

Édition électronique

URL : https://journals.openedition.org/archeopages/575

DOI : 10.4000/archeopages. 575

ISSN : 2269-9872

\section{Éditeur}

INRAP - Institut national de recherches archéologiques préventives

\section{Édition imprimée}

Date de publication : 1 septembre 2014

Pagination : 106-107

ISSN : 1622-8545

\section{Référence électronique}

Victorine Mataouchek, « Un programme original de colombier », Archéopages [En ligne], 39 | 10/2013-01/2014, mis en ligne le 01 janvier 2016, consulté le 24 janvier 2022. URL : http:// journals.openedition.org/archeopages/575; DOI : https://doi.org/10.4000/archeopages.575 
Période

Époque moderne

\section{Un programme original de colombier}

Victorine Mataouchek

Inrap, responsable d'opération, UMR 7324 CITERES

Site

Vesvre, hameau de la Tour Neuvy-Deux-Clochers Cher

Date

16 avril 2014

Surface et hauteur diagnostiquée

$56 \mathrm{~m}^{2}, 6 \mathrm{~m}$ de haut
Le site castral de Vesvre comporte une motte, une vaste basse-cour médiévale, un terre-plein portant tour et logis et une basse-cour moderne [ill. 1]. Cette dernière, ultérieurement transformée en ferme, contient notamment grange, bergerie et colombier. Il s'agit d'un colombier de plan circulaire, attribué à la fin du $\mathrm{XV}^{\mathrm{e}}$ siècle et comportant près de 1 ooo boulins aménagés dès le rezde-chaussée. Le diagnostic réalisé sur les élévations du colombier a révélé que cet édifice participait dès l'origine à la défense de la basse-cour fortifiée, aménagée au-devant de la tour et du logis de Vesvre (Mataouchek, 2014).

Le colombier, construit en même temps que la courtine, est implanté sur le tracé de l'enceinte moderne, à un point où cette dernière oblique subitement [ill. 2]. Le flanquement de la courtine est assuré par trois bouches à feu couvrant, au rez-dechaussée du colombier, les angles d'approche. L'analyse des maçonneries a démontré que ces ouvertures, comme les boulins, dataient bien de la conception de l'édifice. Les embrasures des bouches à feu sont intégrées dans le maillage en quinconce des boulins [ill. 3 a et b]. Il s'agit donc d'une construction bénéficiant d'un programme mixte, associant défense et élevage de pigeons.

Si la construction de colombier est assez prisée dès le retour des croisades, c'est véritablement lors des $\mathrm{XV}^{\mathrm{e}}, \mathrm{XVI}^{\mathrm{e}}$ et $\mathrm{XVII}^{\mathrm{e}}$ siècles que l'on constate un fort engouement pour ce type d'édifice. L'élevage des pigeons répond à trois objectifs. Le caractère symbolique de ces constructions est le plus connu ; en général, ne peut construire un colombier qu'un seigneur ayant droit de justice et suffisamment de terres en propre ou en censive pour les nourrir. Il est d'ailleurs d'usage d'apprécier la taille du domaine au nombre de boulins, suivant un mode de calcul très variable et dicté par les coutumes locales. Le deuxième objectif est celui de l'autosuffisance alimentaire. La possession d'un élevage de pigeons garantit un approvisionnement d'œufs et de viande fraîche toute l'année, à moindre coût. La consommation de viande de pigeon ou pigeonneau est d'ailleurs très recherchée. En 1271, on consomme chaquejour 40o pigeons à la maison du Roi et 300 à la maison de la Reine (Pernot, Doireau, 2008, p. 166). Enfin, le recueil de fiente,

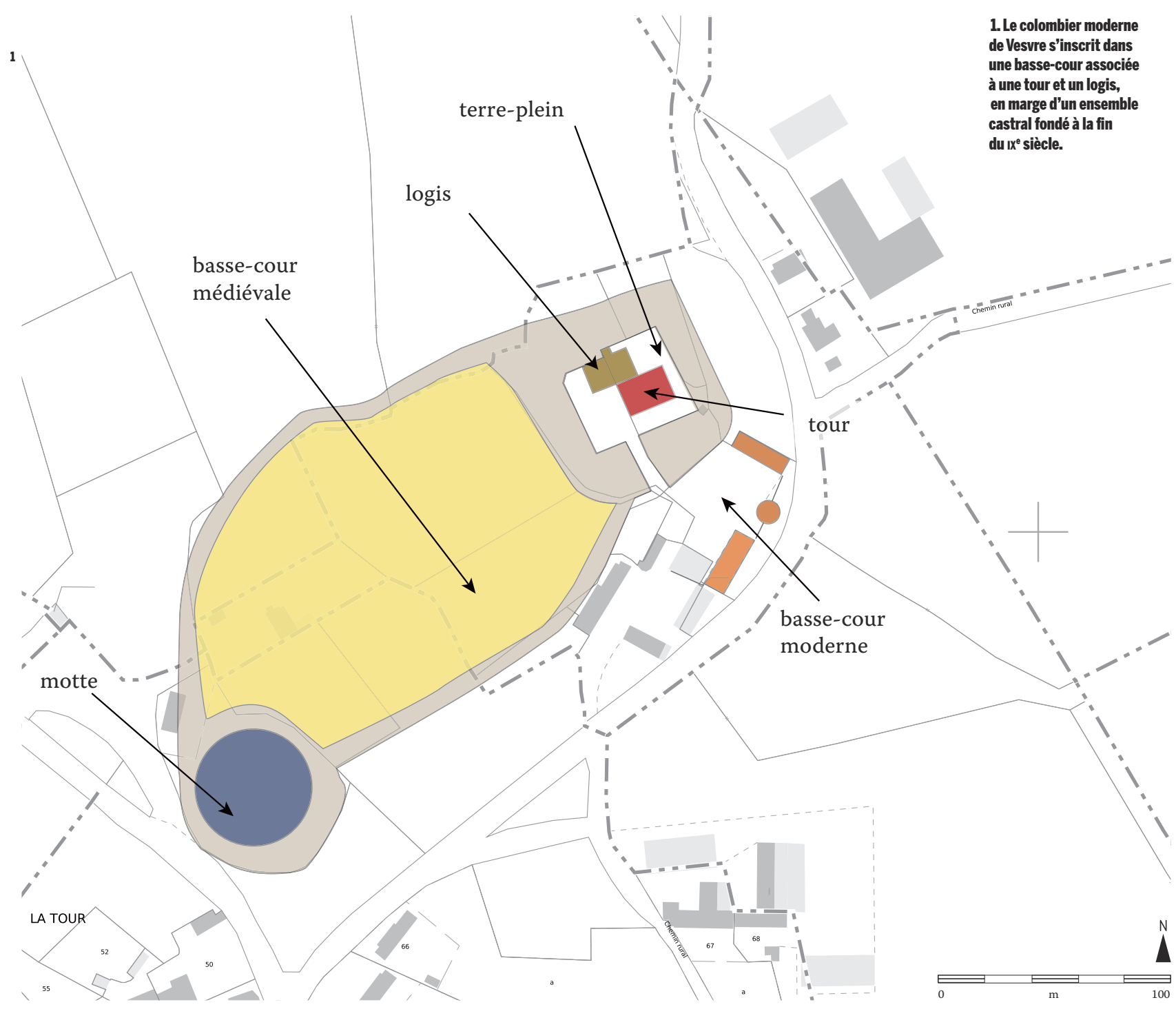




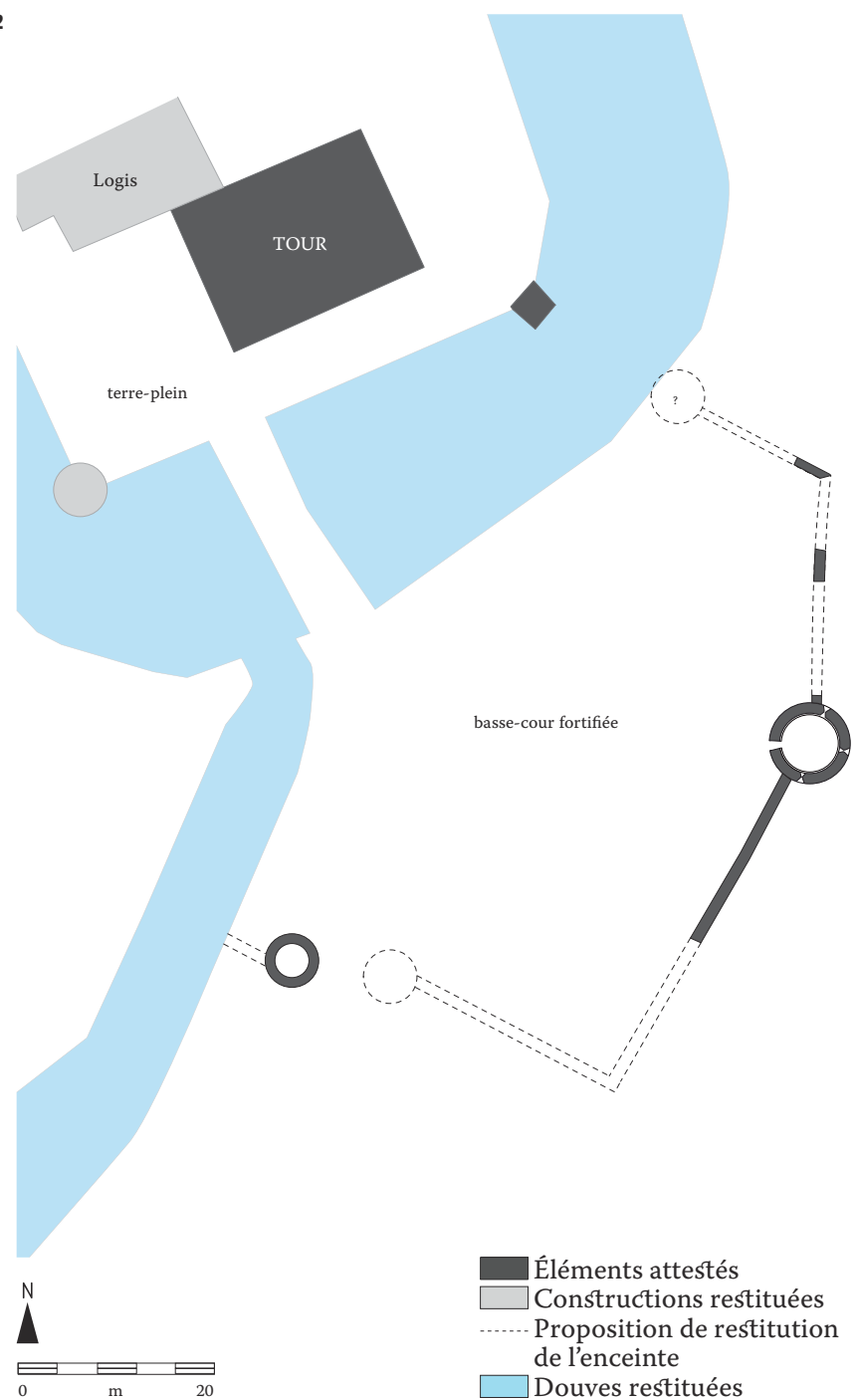

aussi appelée colombine, engrais particulièrement prisé pour la vigne, le chanvre textile et la fumure de jardin, est une source de revenu très appréciable.

Si l'intégration d'un colombier dans une enceinte a déjà été constatée, cette situation reste marginale. À titre d'exemple, sur les 4.07 colombiers et pigeonniers répertoriés dans le département de la Côte-d'Or, seuls $7 \%$ correspondent aussi à des organes de défense (Vandevenne, 2007). Sur l'ensemble des études consultées sur ce sujet, aucun édifice ne présente toutefois les mêmes caractéristiques que celui de Vesvre. En effet, dans chacun des cas rencontrés, le programme est certes mixte, mais les fonctions se répartissent sur des niveaux différents : le rez-de-chaussée est ainsi réservé à la défense, tandis que les boulins sont aménagés à létage. À Vesvre, les deux fonctions se partagent au contraire un seul et même espace.
Cette mixité pose question. Comment concilier exigence de défense et précaution d'usage pour lélevage ? Il est probable que les embrasures des bouches à feu étaient bouchées de l'intérieur pour éviter qu'un prédateur ne puisse rentrer à l'intérieur. De même, on peut penser que le raclage régulier de la colombine devait permettre que le lieu soit relativement sain pour qu'un homme de garde puisse être posté. Toutefois, on imagine mal comment garantir la fidélité des pigeons sur le site et la viabilité de leurs nichées en maintenant sur place une présence humaine. Il est alors probable que ces bouches à feu aient eu un rôle surtout symbolique, visant à montrer que le propriétaire des lieux avait non seulement droit de se défendre. Un symbole dans un symbole donc? de justice mais aussi la capacité
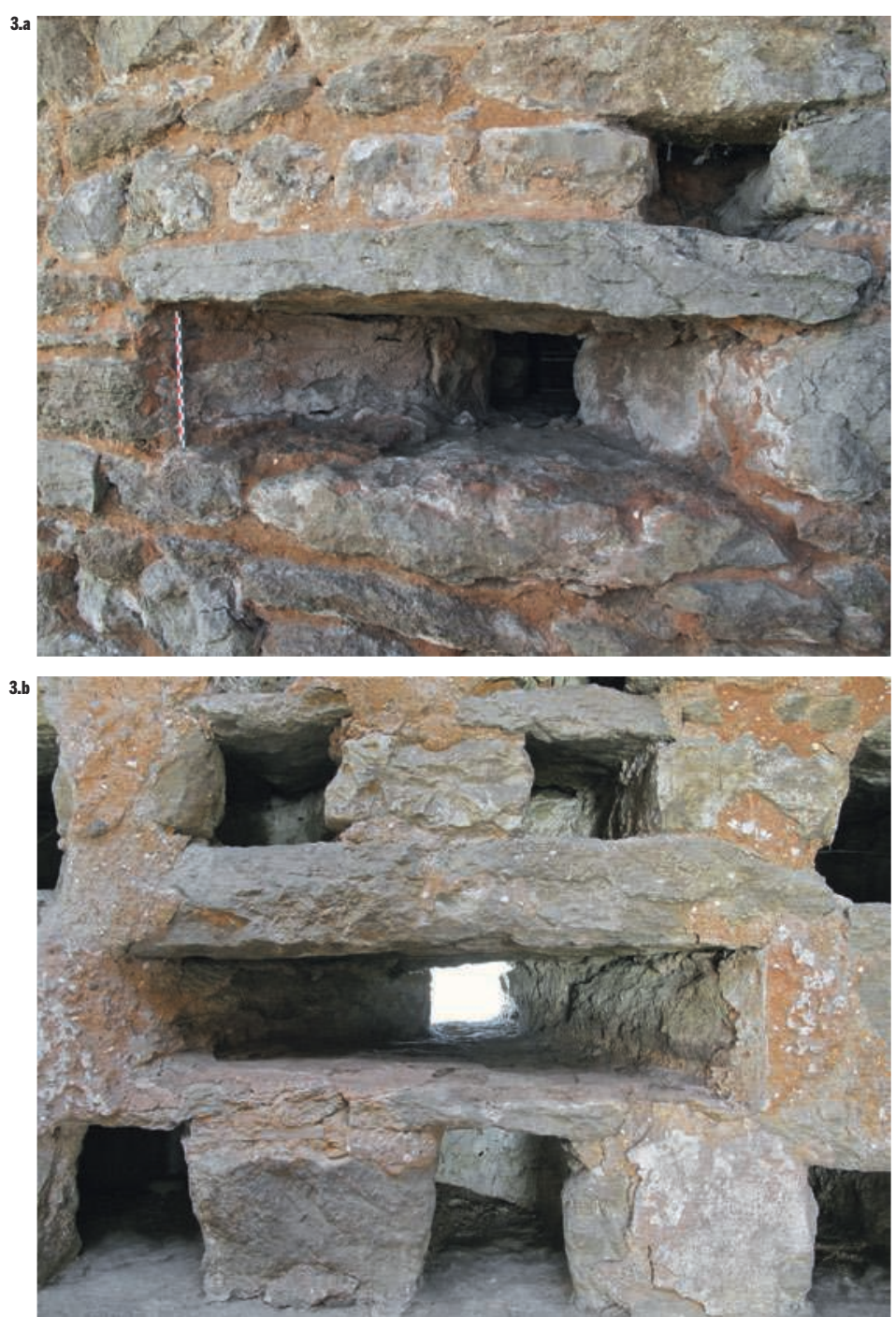

2. Restitution de l'emprise initiale de la basse-cour fortifiée. Situé à l'emplacement où l'enceinte de la basse-cour oblique, le colombier, percé de trois bouches à feu, assure

3. L'ouverture des bouches à feu est insérée, à l'intérieur du colombier, dans le réseau des boulins. 3a. Vue de détail d'une bouche à feu, de l'extérieur. le flanquement de la courtine. 3b. Vue de détail d'une bouche à feu, de l'intérieur.
Références bibliographiques

MataoucheK V., 2014, Rapport de diagnostic archéologique, Neuvy-DeuxClochers, Cher, «La Tour »: Colombier de Vesvre, rapport d'opération, wxInrap-SRA Centre, à paraître.

Pernot M., Doireau P., 2008, Les pigeonniers de Touraine, Chauvigny, Association des publications chauvinoises (Mémoire - Société archéologiques de Chauvigny, XXXII), 203 p.

VANDEVENNE R., 2007, En Bourgogne, découvrir les colombiers et pigeonniers de la Côte-d'Or, Vievy, éditions de l'Escargot Savant, 432 p. 